\title{
Sociedad moderna, mercado y fraude democrático
}

\author{
Modern society, market and democratic fraud
}

Resumen: Abordamos la consistencia interna del fenómeno moderno derecho para poner de manifiesto las consecuencias posibles y efectivas de la vinculación esencialmente contradictoria entre, por un lado, la sociedad moderna, dado su carácter mercantil y, por ende, su estructura capitalista, y, por otro, su propio proyecto racionalizador (en su doble vertiente: derecho y ciencia). Desde el lado jurídico-político, esas consecuencias aparecen a modo de inevitable fraude democrático sistémico, y no ya desde un punto de vista material, como a menudo se reconoce (la realidad socio-económica impide la aplicación efectiva del derecho, de la forma derecho, en alguna medida -según se cree- realmente instaurada, establecida), sino fraude ante todo precisamente a nivel formal: lo que habría de ser el poder civil es sistemáticamente suplantado por un poder pseudo-civil. Muestra evidente de todo ello: nuestras supuestas leyes, supuestas constituciones, supuesto sistema de separación de poderes, supuestas declaraciones de derechos, supuestas democracias, etc. La perspectiva fenomenológica adoptada, con apoyo en el conjunto del pensamiento moderno, aunque de manera destacada en Kant y en Marx, muestra su rendimiento: deja ver al propio proyecto racionalizador moderno como el verdadero e inflexible patrón (auto-)crítico al que la propia sociedad moderna que le ha dado vida no tiene más remedio que rehuir, si no quiere perecer a manos de la revolución socialista.

Palabras clave: sociedad moderna, mercado, estructura capitalista, derecho, ciencia, ética, revolución.

\footnotetext{
Abstract: We address the internal consistency of the modern law phenomenon in order to highlight the possible and effective consequences of the essentially contradictory link between, on the one hand, modern society, given its mercantile character and, therefore, its capitalist structure, and, on the other hand, its own rationalising project (in its two modes: law and science). From the juridical-political perspective, these consequences appear as unavoidable systemic democratic fraud, and not from a material point of view, as it is often recognized (the socio-economic reality prevents the effective application of law, in the legal form, to some extent -according to what is believed- really established), but fraud above all at the formal level: what should be civil power is being systematically supplanted by a pseudo-civil power. An
} 
obvious sign of all this: our supposed laws, supposed constitutions, supposed system of separation of powers, supposed declarations of rights, supposed democracies, etc. The phenomenological perspective adopted, supported in the whole modern thought, especially by Kant and Marx, is showing its performance: it shows the own modern rationalising project as the true and inflexible self-critical pattern to which the modern society that has given it life, has no choice but to shun, if he doesn't want to perish at the hands of the socialist revolution.

Keywords: modern society, market, capitalist structure, law, science, ethics, revolution.

Quizá no estamos aún a la distancia histórica suficiente para poder decidir si el estado de salud de la sociedad moderna es de crisis o más bien de pudrimiento. En todo caso, puede valer la pena a tal efecto retomar el análisis del proyecto específicamente moderno de sociedad igualitaria, el proyecto poder civil, o sea, lo que se suele llamar sistema democrático.

Conste como observación general previa que nuestro tema es ese proyecto en sí mismo, no lo que unos u otros autores o doctrinas han dicho con más o menos razón sobre el mismo. Nuestro objeto no es por ejemplo la filosofía del derecho o la teoría del Estado, sino el fenómeno derecho, con todo lo que él implica; en todo caso, pretendemos hacer una exposición para la que no se requiera erudición alguna, y la razón de fondo puede expresarse como sigue. Aunque todo este negocio se ha ventilado también a nivel doctrinal, lo que la obra de unos u otros pensadores expresa no es sino lo mismo que en el fondo está teniendo lugar en la marcha misma del mundo, en el tener lugar las cosas sin más. El pensamiento esencial, digamos, la filosofía, y todo lo que pueda legítimamente vinculársele desde otros órdenes, como la ciencia o el arte, por ejemplo, no es a fin de cuentas más que el intento de tratar aquello que en el fondo está pasando, aquello que nos está pasando. En este sentido, permítasenos aquí, aunque sólo sea parafrasear aquello de Hegel de que la filosofía, en cierto modo hija de su tiempo, de su época, no es más que su tiempo o su época sólo que expresada en conceptos. ${ }^{1} \mathrm{Y}$ entremos en materia.

\section{El derecho como patrón objetivo de y para la sociedad moderna}

Ya de entrada habrá que notar que el carácter propiamente moderno de ese proyecto jurídicopolítico no presupone nada en cuanto a la posibilidad de su realización o cumplimiento a lo largo de esa etapa histórica, aunque sólo sea en todo caso realización más o menos imperfecta, todo lo cual dependerá de circunstancias históricas diversas. De lo que se trata es sólo de que eso que estamos llamando sociedad moderna lo es en la medida (y sólo en la medida) en que funda ese proyecto o ideal democrático como patrón objetivo con que ella misma presupone que ha de ser enjuiciada, modelo que funcionará pues de manera obvia como rasero. Y esto mismo en rigor nos sitúa en la modernidad a la vez que nos separa de etapas históricas precedentes, incluso por ejemplo de la Grecia clásica, muy socorrida en estos casos para remitir al nacimiento de la "democracia" incurriendo con ello en un manifiesto anacronismo, puesto que

\footnotetext{
1 La cita literal está en la Introducción a Principios de la filosofía del derecho: "En lo que respecta a cada individuo, cada uno es, de todos modos, hijo de su tiempo; de la misma manera, la filosofía es su tiempo aprehendido en pensamientos" (según traducción de J. L. Vermal; Hegel, Principios de la filosofía del derecho, Barcelona, 2005, p. 61).
} 
la polis griega no funciona sobre el supuesto de la igualdad universal que define lo que estamos llamando sistema democrático. ${ }^{2}$

De todos modos, no es lo mismo fundar un determinado modelo de funcionamiento que asumirlo con todas las consecuencias. En efecto, en coherencia con lo que acabamos de decir de que la democracia es moderna pero no automáticamente realidad moderna, es conocido sin embargo que, paradójicamente, la sociedad moderna es precisamente una sociedad esencialmente desigual, por cuanto basada en el mercado, y por tanto con una estructura capitalista que la divide pues en clases, etc. ${ }^{3}$; sociedad que vista desde el prisma de su clase dominante no puede estar ni mínimamente interesada en igualación alguna, digamos, ni económica, ni jurídica, ni política. Desde ese punto de vista, no querrá pues ni siquiera comprobar si supera o no su autoexamen jurídico-político. La bandera de la libertad y la igualdad, etc., quedará atrás, en los tiempos de la lucha burguesa frente al "Antiguo Régimen"; una vez alcanzado el poder político por parte de la burguesía, su sueño igualitario se tornará cada vez más en una pesadilla de la que librarse. Todo lo cual no significa no obstante que la burguesía pueda ni quiera desentenderse sin más de un poder político con algún anclaje en el derecho, que no es otra cosa que la base misma del poder civil, pues sin derecho, tampoco hay mercado, y sin mercado, no hay sociedad moderna ${ }^{4}$ (esto se aclarará más adelante). El caso es que no hay salida de ese callejón.

\section{Inevitable decadencia burguesa: el poder pseudo-civil}

A partir de ahí la situación consistirá en que la clase burguesa necesitará entonces de un poder pseudo-civil de facto que desplazará y mantendrá a distancia como pueda todo proyecto de verdadero poder civil, por así decir, mantendrá a distancia lo que en verdad son derecho, ley, Estado, etc. El derecho, el que pueda o haya podido haber efectivamente en cada momento, llegado a cierto nivel que suponga una amenaza para la entera estructura, habrá de ir siendo convenientemente barrido, eso sí, en nombre del derecho, cualquier veleidad democrática habrá de ser controlada, naturalmente en nombre de la democracia. En una rápida lectura del momento presente, la deriva burguesa decadente abarca fenómenos muy diversos, pero el grueso determinante no puede dejar de ser obra de (y al servicio de los intereses de) la clase dominante, de cuya mano va lo que hace las veces de Estado, esto es, el dominio imperial de las grandes potencias capitalistas, desde el final de la segunda guerra mundial capitaneadas por los EEUU:

\footnotetext{
2 Digamos, resumiendo mucho (pero no podemos entrar en más detalles porque nos saldríamos de nuestro tema) que por ejemplo la polis griega plantea en efecto el problema que andando el tiempo será el de la igualdad política, etc., pero sólo eso, plantea el problema, por lo tanto no lo presupone, no vive precisamente sobre un supuesto marco de igualdad que habría de cumplirse, etc. Además, en particular la expresión griega demokratía tampoco significa ni es en modo alguno homologable a la expresión moderna "democracia” y lo que empezará a significar de manera consistente a partir del siglo XVII (como testimonia el uso por ejemplo en Spinoza) y que tiene que ver, ahora sí, con lo que la modernidad entenderá y entiende cuando emplea rigurosamente esa o expresiones parecidas como, en Marx, "república democrática".
}

${ }^{3}$ Nos remitimos directamente a El Capital, ya desde las primeras líneas: "La riqueza de las sociedades en las que domina el modo de producción capitalista se presenta como un enorme cúmulo de mercancías, y la mercancía individual como la forma elemental de esa riqueza”. (Ed s. XXI, Madrid, 1984, pág. 43)

${ }^{4}$ Repárese en la para nada casual vinculación de "civil" con "burgués". 
control omnímodo de los grandes medios de comunicación; represión y recortes de libertades a gran escala; censura, propaganda y terror organizados a nivel planetario (tendría aquí su hueco por ejemplo el llamado "terrorismo yihadista", nombre con que los mismos gigantes de la intoxicación comunicacional ocultan en estas horas toda una operación de guerra a gran escala no convencional orquestada en secreto por las mismas potencias); organización y/o promoción de golpes de Estado y otras "intervenciones" "humanitarias" en favor de la "oposición democrática" a tal o cual "régimen" "casualmente" incómodo al imperio; diseño y promoción de la figura del intelectual o del activista "comprometido", o sea, pro-imperial, etc. 5

La deriva, obviamente, no tiene por qué ser exclusiva del discurso de la clase dominante. Perdido el pulso combativo de otros tiempos, el pobre contenido jurídico-político del, por así decir, programa de las organizaciones más avanzadas del movimiento obrero irá muy a tono con la putrefacción histórica del propio mundo burgués en general. Las voces que se oigan del llamado ámbito de la cultura, el mundo académico, los intelectuales, periodistas o personajes por el estilo, tampoco han de desentonar en líneas generales a este respecto, claro.

En la hora actual, cómo no evocar por ejemplo el "Índice de libros prohibidos de la Inquisición" cuando oímos justificar todos los días, sin el mayor sobresalto, la calificación delictiva de cosas tales como el "odio", la "apología" o "enaltecimiento" de tal o cual personificación del "mal", la "incitación a la violencia", el llamado "negacionismo", etc., o cuando a menudo retumba esa moralina de censor ante determinados discursos más o menos repugnantes supuestamente incompatibles "con los derechos humanos", o cuando brama la Verdad en persona para reivindicar la censura de "noticias falsas". O cómo no evocar por ejemplo las "cruzadas" o las campañas militares de "evangelización" de las potencias coloniales de ayer, cuando se apela, todos los días, sin mayor sobresalto, a la propaganda de guerra (de las potencias coloniales de hoy) en nombre de la democracia.

\section{3. ¿Qué tipo de fraude democrático?}

Estamos apuntando, con todo ello, a un colapso democrático en un muy determinado sentido. No se trata sin más de que la burguesía diga una cosa y haga realmente otra muy distinta en el sentido de que haya puesto en marcha un proyecto político formalmente democrático pero materialmente inviable o incumplible para ella misma, dados sus intereses como clase dominante. Se trata de fraude democrático antes que nada también necesariamente en la forma. Con otras palabras, la democracia no ya es pisoteada de facto por la realidad material, por así decir, socio-económica, pese a la validez formal de "nuestras leyes", "constitución”, "Estado" o "declaraciones de derechos", sino que es pisoteada ante todo también por nuestras presuntas leyes, constitución, Estado, etc. No hará falta ir a la letra pequeña, la letra y el espíritu manifiestamente antidemocráticos de nuestras "legislaciones", "declaraciones de derechos" y demás, empezando por las más prestigiadas, salta a la vista; sólo hace falta mirar del modo adecuado, es decir, ateniéndose escrupulosamente al propio concepto de derecho burgués,

\footnotetext{
${ }_{5}$ Documentación especialmente pertinente puede seguirse a través de fuentes diversas, que operan, eso sí, a contracorriente. Cf., entre otros, por ej., el trabajo de: Jean Bricmont, Michel Collon, Giulietto Chiesa, Michel Chossudovsky, Daniele Ganser, Eva Golinger, Míkel Itulain (http://miguelesposiblelapaz.blogspot.com/2013/06/el-mundo.html?m=1), Annie Lacroix-Riz, Thierry Meyssan, Jean-Claude Paye, Jacques Pawels, John Pilger, o Isabel Pisano. (ver Bibliografía y Filmografía al final del artículo).
} 
internamente dotado de una consistencia tal que permite definir rigurosamente y armonizar sistemáticamente nociones supuestamente conocidas y asumidas como por ejemplo ley, libertad, límites de las libertades, igualdad, soberanía, división de poderes o constitución, etc. ${ }^{6}$

El que haya claridad en este punto es fundamental para entender en qué podría consistir la alternativa posible al callejón sin salida. Es conocido que la única forma posible de conservar el poder civil se identifica paradójicamente con la destrucción de la propia sociedad burguesa; que ese proceso de conservación es justamente la revolución socialista, y que el artífice de la misma es la propia sociedad burguesa, sólo que vista desde el prisma de la clase dominada, la clase obrera, precisamente aquella que no tiene nada que perder en ese proceso, "salvo las cadenas" decía el Manifiesto Comunista. ${ }^{7}$ Pues bien, no se entendería nada de todo este asunto, si se identifica esa conservación del poder civil con sostén alguno al aparato jurídico-político que opere de facto, es decir, lo que antes hemos considerado "poder pseudo-civil", el cual encaja perfectamente, éste sí, con nuestro supuesto derecho, supuestas leyes, Estado, etc. En nuestra contemporaneidad, sin embargo, la identificación de "nuestra/s democracia/s" con la forma democrática, se asume como obvia casi unánimemente, también a nivel doctrinal, incluso en las posiciones sedicentemente "independientes" o aún "marxistas". Y no se trata obviamente de que exijamos el imposible de que un sistema realmente existente sea a la vez formalmente perfecto. Lo que denunciamos es que "nuestra/s democracia/s", las "nórdicas" incluido, no pretenden en absoluto ajustarse a su objetivo patrón jurídico-político, cosa muy distinta es que lo disimulen mejor o peor.

\section{Consistencia de la forma jurídico-política}

Vamos pues con el modo en que puede ser verdaderamente asumido, y por tanto conservado el poder civil. Para ello tendremos que poner de manifiesto la consistencia de la noción de derecho, y a partir de ahí sacaremos las consecuencias pertinentes a la hora de confrontar con la efectiva realidad jurídico-política del mundo en que nos encontramos.

En este punto es imprescindible no tomar a la ligera los pasos de la argumentación que seguimos. El derecho es la noción de igualdad, como venimos apuntando desde el principio, pero lo es porque define un sistema basado en reglas universales, lo cual significa precisamente el reconocimiento de nuestras diferencias, reconocimiento en virtud del cual esas diferencias son arrancadas al ámbito inmediato, natural, e introducidas en un espacio que es la negación de lo natural por cuanto es la abstracción de ello, un espacio, pues, uniforme, digamos: el espacio civil. En efecto, nuestras en principio diferencias esenciales o naturales, al ser reconocidas para todos y para todos los casos, esto es, universalmente, se convierten en diferencias accidentales,

\footnotetext{
6 Anticipemos que no estamos contraponiendo derecho "positivo" a derecho "natural", cual alternativa que obligara a quedarse con uno de los términos, de modo que pueda terminar ocurriendo que afirmemos tanto la positividad de un derecho positivo que a fuerza de ser positivo deje de ser derecho. Y es que de lo que se trata es sólo de ver qué hay en efecto de la rigurosa noción de derecho en la positiva realidad jurídico-política. Por lo demás, en cuanto a "natural", precisamente la noción moderna de poder civil inseparable de derecho se constituye haciendo abstracción de todo aquello que, de manera inmediata, natural, seamos o podamos ser, sea ángeles o demonios; en eso se basa su carácter universal, como más adelante se explicitará.

7 Nos apoyamos aquí en el planteamiento de Marx, según el cual la revolución no es más que el resultado a que necesariamente aboca la contradicción inherente al sistema capitalista entre lo que el propia Marx llama "relaciones sociales de producción” y su "edificio de ideas y formas".
} 
ya no son lo sustancial, conquistándose así un espacio uniforme, igual: todos somos diferentes, cada cual es, por así decir, singular, una excepción, de acuerdo, pero eso lo somos todos por igual. Tenemos ya aquí la copertenencia de igualdad y libertad constitutivas del derecho. La igualdad en el sentido del reconocimiento universal de las diferencias, por así decir, el derecho igual como el derecho a la desigualdad. Con otras palabras. No se nos reconoce tal o cual derecho en función de si somos tal o cual persona o hacemos tal o cual cosa, lo único que importa es que la libertad que se me ha de garantizar a mí, en principio la que sea, lo sea en la misma medida en que también, bajo las mismas condiciones, se le garantiza a cualquier otro.

Pero, no olvidemos que la forma jurídica no llueve del cielo, sino que es condición para que pueda haber mercado, es decir, circulación universal de mercancías ${ }^{8}$. En efecto, para que toda cosa pueda ser efectivamente alienable o intercambiable por cualquier otra es imprescindible que los agentes en ese intercambio tengan la total libertad de intercambiar sólo limitada por el hecho de que esa libertad sea universal, de que, digamos, mi libertad de intercambio sea compatible con la de cualquier otro. Y esa libertad por igual es inseparable a su vez del concepto de propiedad: algo me es propio, o es de mi propiedad, en la medida en que puedo tratarlo como ajeno, en la medida en que puedo, si quiero, desprenderme de él, enajenarlo, intercambiarlo, venderlo. Y ya tenemos, como eslabones de una misma cadena la igualdad, la libertad, pero también la propiedad.

Nos extralimitaríamos aquí si entrásemos con algún detalle en la demostración de que la propia circulación universal mercantil es inseparable de la generación de la plusvalía y su apropiación por parte la clase burguesa, y por tanto de la necesidad de la explotación, de modo que el sistema se basa en la división en clases a la vez que en su contrario: la exigencia de igualación o, por así decir, de racionalización política. ${ }^{9} \mathrm{El}$ mismo proceso estructuralmente contradictorio también puede seguirse por el lado de la racionalización científico-técnica. ${ }^{10}$ Pero no nos salgamos de nuestro asunto.

Digamos para ir cerrando una definición consistente del derecho lo que sigue. Ese espacio civil, uniforme, abstracto, exige que haya una fuerza que garantice el ejercicio de la libertad por igual: el Estado, cuyo papel no sólo es indispensable desde el punto de vista del funcionamiento eficaz del sistema, sino también por ello mismo desde el punto de vista de la justicia: la obligación que yo tengo de respetar la libertad del cualquier otro se identifica con la garantía de que cualquier otro respeta la mía, y eso sólo es posible si la fuerza coactiva garante de la universalidad de las libertades es superior a la de cualquiera de los que ejercen sus libertades.

La llamada separación de poderes también se deduce del mismo esquema. Un sistema basado en la universalidad de la norma, en leyes cuyo cumplimiento ha de garantizar universalmente el Estado, no juzga más que aplicando al caso particular la norma general que rige de antemano para todo caso que esté en las mismas condiciones definidas en la norma. Y eso sólo es

\footnotetext{
8 "La relación jurídica, cuya forma es el contrato, es una relación entre voluntades en la que se refleja la relación económica” (K. Marx, El capital, Siglo XXI, cap. II, “El proceso del intercambio”, p. 103).

${ }^{9}$ La demostración de todo ello es El Capital de Marx.

${ }^{10} \mathrm{El}$ proceso de racionalización científico-técnica y, por tanto, la tendencia a someter todo el aparato productivo a un solo plan, también es impulsado a la vez que frenado por la esencial irracionalidad mercantil. Ésa es la contradicción que atraviesa al capitalismo, según la conocida fórmula de Marx, entre sus "relaciones sociales de producción” (apropiación privada de los medios de producción, anarquía mercantil) y el "desarrollo infinito de las fuerzas productivas".
} 
possible, por definición, si esa norma tiene la forma lógica de universalidad, es decir, si esa norma es independiente (abstractiva) de cualquier contenido o cualquier uso de la libertad reconocida universalmente, caso contrario incurre en limitaciones arbitrarias liquidadoras de la libertad. Y entonces por definición, no es el mismo acto pues el de juzgar que el de elaborar la norma a aplicar por igual a cada caso particular. Sólo el déspota juzga directamente, sin mediar universalidad alguna, sobre el caso singular; lo cual por definición es contrario a cualquier garantía, cualquier seguridad. Aún añadiremos algo más a este respecto más adelante en contexto con la ética.

Y también del mismo esquema tiene que desprenderse la identidad de poder civil, poder soberano, soberanía o autodeterminación. Abordamos todo ello más abajo, en el contexto de la confrontación con la realidad supuestamente democrática.

\section{La democracia ha muerto, ¡viva la democracia!}

Y bien, decíamos ya en el comienzo que no es lo mismo fundar el modelo democrático que asumirlo con toda consecuencia. ¿Qué tendría pues que pasar para eso, para que no se incurriere en el fraude democrático, y se caminare así en la dirección de salvar el proyecto poder civil? Veamos. Ese modelo abstracto, igualador, uniformizador (y ya hemos visto que es todo eso porque reconoce las diferencias universalmente), es lo que la modernidad pone como su concepto de humanidad, como criterio para definir lo que es, digamos, el hombre ${ }^{11}$. Con otras palabras, los humanos lo son en la medida en que son por igual libres. Es decir, han de ser libres, cada cual ha de ser libre en lo que hace, dice, en definitiva, en lo que es, sin límites, o sea, con el único límite implícito de que lo sea sin que ello impida que cualquier otro también pueda serlo. No se entra, no se puede entrar, en los contenidos de las libertades, hay que abstraer pues el uso que yo o cualquier otro hagamos de nuestra libertad, lo único que se nos exige, el único límite, es que no se usen otros medios que el de la libertad. Y eso es lo que significa el que los límites son sólo formales: mientras me conduzca dentro de la forma de la libertad de expresión, por ejemplo, es decir, mientras me exprese y sólo me exprese, es indiferente lo que yo libremente exprese, y lo mismo para el resto de libertades (reunión, asociación, manifestación, voto), etc.

\footnotetext{
11 En paralelo con lo que ocurre en el plano de la conducta, de las relaciones humanas, en el plano del conocimiento, la modernidad funda a un tiempo la física-matemática como el concepto moderno de ciencia, esto es, como modo de entender las cosas, la naturaleza. Según ese concepto de ciencia, el objeto de conocimiento será entendido como lo dominable en el sentido de lo reductible a relaciones cuantitativas o expresable en términos matemáticos; de modo que las cosas pierden (aquí también) sus diferencias y cualidades propias como se las entendía hasta el final de la Edad Media, para entenderlas sólo desde sus diferencias cuantitativas, por tanto todas subsumibles en un mismo plan o ámbito uniforme. Las leyes generales de la física son expresión del mismo prisma científico; por ejemplo, el principio de relatividad del movimiento no es más que la exigencia de que ningún punto fijo desde el que describir los movimientos lo sea en términos absolutos, todos los puntos son igualmente asumibles como punto fijo, todo dependerá de dónde quiera situarse el observador; caso contrario, y aquí está la clave, sería imposible expresar matemáticamente el movimiento; y esto es lo que hace posible, como es bien conocido, el célebre giro copernicano. De modo que, en definitiva, no puede escapársenos la relación esencial de todo ello con la lógica mercantil inherente a la estructura capitalista: el mercado -como demuestra Marx- es inseparable de la reductibilidad de todos los valores a "sustancia valor", de todos los trabajos, a trabajo abstracto (y por lo mismo, inseparable de la exigencia, contraria al mercado, de la racionalización/planificación productiva), etc.
} 
El sistema democrático entero, leyes, Estado, etc., ha de seguir rigurosamente esa misma pauta niveladora por cuanto abstractiva. Es evidentemente contrario a todo ello el que además de que yo haya de respetar la libertad de cualquier otro, tenga que respetar más cosas, porque por definición, en ese respeto universal de la libertad está implícitamente incluido todo, o sea, todo lo que el hombre pueda ser o no ser, querer o no querer, etc. Esa libertad queda completamente anulada si a su vez ha de ser limitada para que presuntamente no sean dañados otros valores o bienes supuestamente mayores, pongamos, por ejemplo, "el orden público", "el honor", "la intimidad", "los derechos humanos" o hasta la "democracia" misma. Es de toda lógica que si se me reconoce la libertad de expresión, pero se la limita con, por ejemplo, "el respeto de la democracia", se está incurriendo en el terrible absurdo de contraponer a la democracia misma "el respeto a la democracia", o con otras palabras: la democracia hay que limitarla o suprimirla en virtud de que es contraria al "respeto a la democracia". ¿Qué está sucediendo, de esta guisa, con el sistema democrático? Pues que evidentemente ha dejado de ser el criterio, pasando ahora el ser humano a ser definido por criterios por definición antidemocráticos, como, en el ejemplo, la expresión respetuosa con la democracia, con los derechos humanos, etc. Y todo esto es lo que sucede sistemáticamente en nuestras leyes y declaraciones de derechos de nuestros días: nuestras presuntas libertades son eso, presuntas, porque son limitadas a cada paso por cosas como "los derechos humanos", "el orden público", "la intimidad", "el honor", "la imagen" ... Emitir por ejemplo expresiones respetuosas con los derechos humanos a la fuerza (u omitirlas a la fuerza las irrespetuosas) no es ningún respeto a los derechos humanos. Qué otro orden público o qué otra seguridad puede haber, en rigor democrático, más que los que por definición implica el que esté yo obligado a respetar la libertad de cualquier otro (que a su vez está obligado a respetar la mía). Si se respeta mi libertad, no se ve cómo puede invadirse mi intimidad. ¿Qué más honor o imagen quiere uno que el que se le respete su libertad, y nada más que su libertad, no, al menos no a la fuerza, sus gustos ni sus ideas, etc.? ¿Qué más respeto por ejemplo a la memoria de alguien o de la humanidad entera que el que el respeto no lo sea porque hay riesgo de multa o de pena de cárcel?; a este respecto, por ejemplo, resulta especialmente denigrante para las víctimas de la represión de una dictadura, etc., el presunto respeto que se les profesa en virtud de la coacción impuesta por una "legalidad" que en ese punto pasa a ser homologable a la de la dictadura a la que pretende haber superado. Etc.

\section{El problema de la autodeterminación}

Hemos dicho que la noción rigurosa de derecho se constituye haciendo abstracción de todo aquello que de manera inmediata, natural, seamos, hagamos, etc., formándose así una especie de sujeto abstracto, sin cara ni ojos, sujeto cuya voluntad no es más que la "voluntad general", y que no puede depender por tanto, para constituirse en sujeto de la "voluntad general", más que de las voluntades que lo constituyen, y no de rasgo o carácter particular alguno; todos esos rasgos particulares son abstraídos en la construcción del sujeto colectivo, si no, no sería éste el soberano en término democráticos, es decir, no puede depender de si tiene (que siempre los tiene, unos u otros) tales o cuales rasgos sociales, lingüísticos, culturales, históricos, etc.

Todas las voluntades particulares que han terminado disolviéndose en el soberano o "sujeto constituyente" lo han hecho mediante un pacto, es decir, lo han hecho por su voluntad, por la misma por la que pueden volver sobre sus pasos, si no, no estaríamos hablando de pacto o voluntad general. De modo que quien decide sobre la autodeterminación de, por ejemplo, una 
determinada región de un Estado es sólo la población de dicha región y no, por tanto, el conjunto de la población de ese Estado en virtud del pseudoargumento de que ése es el "sujeto constituyente", pues precisamente la voluntad de autodeterminarse de dicha región pone en cuestión al sujeto constituyente, y no puede poner en cuestión democráticamente al sujeto constituyente más que las voluntades de las partes, no ninguna otra razón histórica, cultural, legal, etc. Caso contrario se estaría atribuyendo un carácter "natural" o "eterno" al presunto soberano en función de rasgos particulares determinados que ya no serían abstraídos sino decisivos. Con un ejemplo de cierto tipo de contrato, el matrimonio: sólo la voluntad reúne a los particulares en el matrimonio, la separación sólo ha de depender pues de que uno de ellos la quiera, si no, no hay en verdad contrato, sino pura imposición. Puede haber desde luego "leyes" que se opongan a ello, pero eso no las califica de democráticas, y la democracia no puede depender de presuntas leyes por muy unánimemente que hayan sido respaldadas. El respaldo social de una ley nos lleva fuera del terreno jurídico, en concreto al, no menos importante, estricto terreno político. Y es desde ese otro punto de vista, desde el que se plantea legítimamente la cuestión de la pertinencia política (no jurídica) de la reivindicación de la autodeterminación en tal o cual momento histórico y lugar; o con otras palabras, de si, en según qué circunstancias o situación histórica, enarbolar la bandera de la autodeterminación es una mera artimaña o una operación artificial, etc. No de otra cosa que de esa pertinencia política era de lo que discutían Lenin y Rosa Luxemburgo; viene esto de paso a responder a la interesada interpretación que suele circular según la cual Rosa Luxemburgo rechaza la validez jurídica del "derecho de autodeterminación", lo cual es imposible cuando todo su argumento en defensa del sistema democrático supone implícita y explícitamente la identidad de sistema democrático y autodeterminación.

Por lo demás, los representantes del fraude democrático no pueden echar por la borda sin más el derecho de autodeterminación o soberanía, lo único que ocurre es que lo anulan en la misma medida en que sólo son capaces de usarlo contradictoriamente, o sea, sólo a su favor, y no por tanto como principio, sino sólo como "derecho" de imponer un determinado pacto o contrato a otro presunto contratante que en ese mismo instante pierde por ello mismo su carácter de contratante o de integrante de pacto alguno y pasa a ser sólo, si es el caso, víctima de una pura imposición. Y en este uso contradictorio del principio de autodeterminación en que éste deja de ser principio y por tanto deja de ser a secas, se expresa la misma contradicción que late en el fondo de la sociedad burguesa en su fase decadente y que la incapacita absolutamente para asumir el derecho con toda consecuencia.

\section{A modo de ilustración}

Sirva para ilustrar el fraude democrático de nuestros días algún ejemplo especialmente indicativo de cuál es la situación general. Una simple inspección de lo que formula la Declaración Universal de los Derechos humanos (1948) ha de conducir a un atento lector a percibir ahí mismo una manifiesta apología de la supresión de los derechos. Después de un comienzo prometedor (art. 2), donde se nos reconocen derechos y libertades "sin distinción alguna de raza, color, sexo, idioma, religión, opinión política...", se cierra (art. 29.2) "sujetando" esos derechos y libertades 
a las limitaciones establecidas por la ley con el único fin de asegurar el reconocimiento y el respeto de los derechos y libertades de los demás, y de satisfacer las justas exigencias de la moral, del orden público y del bienestar general en una sociedad democrática.

Es evidente el timo consistente en considerar que (insistimos en lo dicho arriba) el respeto a las libertades, a las "justas exigencias de la moral", el orden público y el bienestar general no se suponen ya incluidos en el ejercicio universal de los derechos y libertades.

Otro tanto ocurre con la Constitución Española vigente (1978). Sin ir más lejos, si uno se fija por ejemplo en el artículo dedicado a la libertad de expresión (art. 20), no tiene más remedio que concluir que se trata como mínimo de enaltecimiento de la censura. Después de afirmar el reconocimiento de ese derecho, entre otros, el punto 4 fija el límite en: "el respeto a los derechos reconocidos en este Título, en los preceptos de las leyes que lo desarrollen y, especialmente, en el derecho al honor, a la intimidad, a la propia imagen ...". La contradicción es flagrante. ¿Qué más respeto a los "derechos reconocidos..." que ejercer la libertad de expresión?

En líneas generales, puede decirse que habría que remontarse a las leyes de épocas revolucionarias, bien revolucionarias burguesas o bien obreras, para encontrarnos de verdad con el derecho, no en estado puro, porque eso ya hemos anticipado que no es posible por definición en el mundo real, pero sí de manera relevantemente apreciable.

Viajemos por un momento a la revolución francesa. Fijémonos por ejemplo en el artículo 4 de la Declaración de los Derechos del Hombre y del Ciudadano (1789):

La libertad consiste en poder hacer todo aquello que no perjudique a otro: por eso, el ejercicio de los derechos naturales de cada hombre no tiene otros límites que los que garantizan a los demás miembros de la sociedad el goce de estos mismos derechos. Tales límites sólo pueden ser determinados por la ley.

Puede parecer también que se limita la libertad (los contenidos de la libertad o el uso de la libertad) que de entrada se reconoce. Pero no, en absoluto. Aquí sólo se trata de que la libertad de cada cual "no tiene otros límites que" la de cualquier otro, y esos mismos límites ("tales límites" dice el texto, con subrayado nuestro) son los que tendrán formulación universal, esto es, serán recogidos en forma de ley. De modo tal que los límites son sólo formales, no entran en el contenido o uso que hagamos de nuestra libertad. Se puede tal vez redactar mejor, pero así mismo resulta impecablemente preciso.

Y ahora vayamos a la Rusia bolchevique. En concreto al tratamiento de la libertad de expresión. Constitución de la República Socialista Federativa Soviética de Rusia (1918), artículo 14: “A fin de asegurar a los trabajadores la verdadera libertad de expresar sus opiniones, la RSFSR suprime la dependencia de la prensa respecto del capital, repone en manos de la clase obrera y los campesinos pobres todos los recursos técnicos y materiales necesarios para la publicación de periódicos, libros y otras producciones de prensa, y garantiza la libre difusión de estos y aquellas en todo el país." Se trata de difusión libre (el subrayado es nuestro), y sin límites, ni siquiera económicos: el texto expresa la necesidad de suprimir la dependencia de las posibilidades materiales de expresión respecto de la existencia misma de las clases, o sea, la necesidad de superar la división social en clases. 


\section{Qué decir de la ética}

A todo esto, podría quizá preguntarse dónde queda la ética, y en concreto la ética política ante un poder civil obligado a no juzgar nuestra conducta, esto es, los contenidos de la libertad (el qué hago o dejo de hacer, etc.), precisamente porque ha de limitarse a garantizar sólo universalmente la libertad (el que la mía sea compatible con la de cualquier otro). Respuesta: pues precisamente la ética de la fuerza coactiva y de todo el poder civil reside en abstenerse de juzgarnos moralmente, dado que lo único de nuestra conducta que es accesible, modificable, coactivamente, es su faceta material o externa, no su faceta moral o interna. Con otras palabras, el que es castigado por un crimen, por ejemplo, no recibe el castigo porque su conducta ha sido moralmente mala, puesto que en ese caso también habría de recibir igual castigo el que no ha cometido un crimen sólo por evitar el castigo; si es fundamentalmente sólo por eso, se trata de una conducta de igual modo moralmente reprochable. El castigo responde pues a una violación del límite sólo de la libertad de alguien. Y en cualquier caso, pretender juzgar y condicionar vía coacción la conducta moral entraña un absurdo manifiesto: en efecto, es imposible hacer algo bueno moralmente porque así evito el castigo, es decir, por interés, porque ese mismo interés desmiente el carácter moralmente bueno de la conducta.

En cualquier caso, la pretensión de juzgar los contenidos de la libertad (o de juzgar intrínsecamente la conducta) es lo mismo que juzgar contra la universalidad de la norma, y si no se juzga con arreglo a normas universales, no puede haber división de poderes, ni garantía universal de la libertad, ni por tanto verdadero Estado garante de libertad alguna, sino pura imposición despótica. Sin verdaderas leyes no hay stricto sensu separación de poderes, por mucho que el déspota vista con distinto atuendo en función de si está emitiendo una de sus leyes o dictando una de sus sentencias.

Sólo tratamos de ilustrar con algún ejemplo la verdadera definición de lo ético en el mundo moderno: la imposibilidad de conocer o condicionar o manipular más que la conducta material, imposibilidad en que se basa ese abstenerse de hacer juicios morales propio del derecho moderno. Lo ético o lo moral, podríamos concluir, es no entrar en lo moral.

A propósito, hagamos una pequeña aclaración teórica. Estamos manejando de fondo el concepto moderno de ética autónoma. ${ }^{12}$ El que en la modernidad la ética sea autónoma significa que el enjuiciamiento moral de la conducta es interno a la misma, cada decisión que tomamos se enjuicia moralmente a sí misma, o lo que es lo mismo, es inaccesible al (e independiente del) conocimiento. Para que se pudiese llegar a conocer (y juzgar externamente, por cuanto desde el conocimiento) qué decisión ha tomado alguien en el fondo en un determinado caso (cuál es su máxima en ese caso -en términos de kant), habría de saberse qué haría ese alguien independientemente de toda circunstancia, pero eso no es posible ni siquiera para ese alguien porque siempre estamos ante unas $\mathrm{u}$ otras circunstancias, nunca ante toda circunstancia ${ }^{13}$. En la

\footnotetext{
12 Concepto culminantemente formulado en Kant, y que se basa en la escisión irreductible entre el campo cognoscitivo o fenoménico (coactivo) y el moral (inasequible a la coacción); escisión que no es patrimonio de doctrina moderna alguna, sino que atraviesa al mundo moderno en general, y no sólo doctrinalmente; el mismo asunto también se conoce doctrinalmente como "ley de Hume".

${ }^{13}$ Este tipo de consideraciones se siguen en Kant, Crítica de la Razón práctica, en concreto en la parte dedicada a la Dialéctica...
} 
Antigüedad o en etapas posteriores premodernas, lo obvio es lo contrario: conocimiento y conducta van de la mano, conocer una cosa es inseparable de saber qué hacer al respecto. En la modernidad sin embargo, lo obvio es que el conocimiento es moralmente neutral; por ejemplo, tan conocimiento sobre la salud es saber curar la enfermedad como saber producirla; conocer es independiente del fin que persigamos, de nuestros fines. En definitiva, la ética moderna se corresponde con el conocimiento propiamente moderno que asume su objeto como algo reductible, dominable (cf. nota núm. 12). ${ }^{14}$ Retomamos ahora el hilo argumental.

Con todo, quizá cabría otra posible objeción a nuestro planteamiento. Pues, podría quizá suponerse que la libre actividad de unos u otros puede no impedir o forzar la libertad de los demás, pero sí puede incitar a que cualquier otro impida o fuerce la libertad..., con lo cual -se podría hipotéticamente objetar-, habría que restringir ciertas libertades que conlleven tal supuesta incitación. La garantía de la libertad -se supone en ese caso- sería absoluta. Por ejemplo, considérese a tal efecto la hipotética limitación o restricción de cierto uso de la libertad de expresión en tanto que "puede incitar a la violencia", etc. Pues bien, respondemos que no es posible ese tipo de restricciones de la libertad sin acabar ipso facto con la misma. En efecto, busquemos como ejemplo un caso extremo: ¿qué comporta prohibir cierto discurso en favor por ejemplo del genocidio o de la guerra u otras intervenciones del "imperialismo humanitario" de nuestros días? Comporta ni más ni menos que la destrucción de todo el edificio democrático por varios tipos de razones, pero que son expresión de lo mismo: por empezar por algún punto, supone suprimir la libertad de todo aquel que quiera escuchar ese tipo de discurso, aunque sólo sea por mor de combatirlo mejor; a la vez, toda expresión en sentido distinto o contrario a ese discurso no será libre, sino obligatoria (sólo se es libre de expresar algo, si se es libre de expresar lo contrario que ese algo); además, la sociedad entera habrá pasado a ser una sociedad vigilada, no libre, pues cualquier conducta puede ser sospechosa de "incitación"; resuena aquí aquella advertencia de Hegel: pretender garantizar absolutamente la libertad es tanto como suprimirla... Por lo demás, siguiendo en clave ilustrativa, también podríamos nosotros objetar a la contra preguntando si bajo el paraguas del presunto delito de incitación... también podría cobijarse alguna suerte de "delito de incitación sexual" o "erótica" o algún disparate por el estilo al que agarrarse para eximir en alguna medida de responsabilidad al acusado por agresión sexual, etc.

Añadamos por último que en todo caso la citada prohibición del ejemplo es además rigurosamente ineficaz, pues sólo podemos impedir que se difundan ciertas funestas ideas impidiendo las ideas contrarias a esas funestas ideas; es como aquel imposible de tratar de concebir la noche sin el día, el invierno sin el verano, la tormenta sin la calma, etc.

En fin, lo que pretendemos subrayar es que asumir consecuentemente la idea de libertad universal no significa obligación alguna de ir proclamando las bondades de la libertad o la democracia o etc., sino asumir precisamente que no hay obligación de proclamar ni de callar tal o cual expresión; y lo mismo para el resto de libertades fundamentales. El que cierto tipo de expresiones o ideas o engendros gocen de gran difusión no radica en que no estén prohibidas,

\footnotetext{
14 Todo ello encaja con el postulado también moderno de que no tiene por qué haber fines comunes, pero sí, por ello mismo, un interés común que permita que cada cual pueda perseguir su/s particular/es fin/es, interés común que se expresa en la necesidad del pacto, la edificación de un sistema de garantías, basado por ello mismo en reglas universales, etc.; y esto nos sitúa ya en la sociedad moderna en marcha, y, a nivel de pensamiento, nos sitúa en primer plano ante Hobbes y Spinoza.
} 
sino en que las expresiones o ideas que pueden combatirlas están censuradas, o bien porque lo establece la "ley" o bien porque el poder económico-político de facto no tiene interés alguno en que aparezcan en los grandes medios de comunicación, por ejemplo.

\section{9. ¿Dios ha muerto?}

Empezamos señalando la irreductible distancia entre, por un lado, la fundación de un determinado proyecto histórico como el que representan la ciencia y el derecho para la sociedad moderna, el patrón objetivo de y para la sociedad moderna, y, por otro lado, la consecuente asunción del mismo por ella misma. La irreductibilidad se expresa en que el único cumplimiento posible del ideal proyectado significaría la liquidación misma del propio mundo que lo proyecta, para el caso, el cumplimiento del ideal de racionalidad comporta suprimir la estructura desigual (irracional) que en principio le servía de base: sociedad mercantil, por ello, dividida en clases, anarquía productiva, etc. Al cumplimiento es a lo que Marx llama revolución. Cumplimiento que es a la vez la definición, y por ello, el final, propiamente correspondiente a la sociedad moderna. En ese sentido proyecto revolucionario y filosofía se identifican con esa situación definitoria a la vez y por ello mismo liquidadora de la modernidad: ambas cosas consisten en reconocer no ya esta o aquella cosa, sino aquello que es la esencia de las cosas, la esencia del mundo moderno en este caso, por cuanto la esencia de algo es lo que lo define, y lo que define o delimita una cosa aparece en el fin de la cosa definida, en este caso en el fin del mundo moderno, en la muerte de la sociedad burguesa.

Pues bien, eso que llamamos racionalidad es, como hemos ido mostrando a lo largo de estas líneas, un modo tal de considerar y tratar las cosas, y las relaciones humanas, que reduce las diferencias a diferencias meramente accidentales, donde lo único esencial es el ámbito o la magnitud común que las envuelve, pero cada cosa en sí misma, por separado, es ajena a la racionalidad, por así decir, no es esencialmente nada, no vale esencialmente nada, sino sólo en cuanto reductible bajo un mismo parámetro que todo lo demás. La única salida valida esencialmente ante esa situación nihilica general es en Marx la revolución, esto es, la única salida no nihílica consiste en asumir la nihilidad, asumir el patrón objetivo al que nos referimos desde el principio. En Nietzsche, aunque bajo una formulación distinta, se plantea la asunción de la nihilidad como la asunción del hecho de que "Dios ha muerto".

Volviendo, ya para acabar, al derecho, la actitud que no reconoce esa nihilidad es la que persiste en creer salir del abismo en que está y que en el fondo desconoce otorgando arbitrariamente valor a alguna cosa frente a otras (algo homólogo sucede del lado socio-económico: por ejemplo cuando se sueñan "grandes transformaciones" que ni rozan la ingobernable estructura económica). En el ámbito jurídico-político esa actitud es la que se expresa en favor en alguna medida de las restricciones de las libertades "porque no puede ser que todo dé igual", que "todo sea relativo", "no todas las opiniones -se dice- son respetables", "no todo vale", y entonces se busca algún presunto criterio tomando esta o aquella opinión como la sagrada, o esta o aquella como sacrílega. Para el caso, es evidente que cada opinión o expresión o idea tiene su valor propio, pero eso fuera del derecho, desde el punto de vista del derecho son iguales, pero sólo desde ese punto de vista, es decir, abstrayendo lo que esas opiniones o expresiones o ideas puedan ser en otros terrenos. 
La cuestión es asumir la muerte de Dios o seguir profesando la necrofilia divina, como vendría a decir Nietzsche. Socialismo o barbarie, diría Marx.

\section{Bibliografía}

Bricmont, J. (2009) Impérialisme humanitaire. Droits de l'homme, droit d'ingérence, droit du plus fort? Bruselas: Aden.

Chiesa, G. (2007). Zero. Perché la versione ufficiale sull'11/9 è un falso. Segrate (Lombardia): Piemme.

Chossudovsky, M. (2016) La globalización de la guerra: la "guerra larga" de EEUU contra la humanidad. Managua: PAVSA.

Chossudovsky, M. (2005). America's "War on Terrorism”. Pincourt (Quebec): Global Research.

https://www.dropbox.com/s/hhz6z304tmii3qt/Globalizaci\%C3\%B3n\%20de\%20la\%20guerra\% 20-\%20Michel\%20Chossudovsky.pdf?dl=0 (visita 9-12-2019).

Collon, M. (1999). El juego de la mentira. Las grandes potencias, Yugoslavia, la OTAN y las próximas guerras. Hondarribia (Gipuzkoa): Hiru.

Ganser, D. (2010). Los ejércitos secretos de la OTAN. Barcelona: El Viejo Topo.

Golinger, E. (2009). La telaraña imperial. Enciclopedia de injerencia y subversión. Caracas: Monte Ávila.

Hegel, G. W. F. (2005). Principios de la filosofía del derecho. Barcelona: Edhasa.

Hobbes, T. (2005). Del ciudadano y Leviatán. Madrid: Tecnos.

Kant, I. (2004). Crítica de la razón práctica. Madrid: Alianza.

Kant, I. (1989). La metafísica de las costumbres. Madrid: Tecnos.

Kant, I. (1985). Crítica de la razón pura. Madrid: Alfaguara.

Lacroix-Riz, A. (2012). L'histoire comtemporaine toujours sous influence. Paris: Les Temps de Cerises.

Martínez Marzoa, F. (2003). Historia de la Filosofía. Madrid: Istmo.

Martínez Marzoa, F. (2018). La filosofía de El Capital. Madrid: Abada.

Martínez Marzoa, F. (2008). El concepto de lo civil. Santiago de Chile: Metales Pesados.

Martínez Marzoa, F. (1992). De Kant a Hölderlin. Madrid: Visor.

Martínez Marzoa, F. (2011). Distancias. Madrid: Abada.

Marx, K. (1984). El capital. Madrid: Siglo XXI.

Marx, K. (2008). Contribución a la crítica de la economía política. Madrid: Siglo XXI. 
Meyssan, T. (2017). Sous nos yeux. L'effroyable imposture des "printemps arabes", France: Demi-lune.

Nietzsche, F. (2019). La gaya ciencia. Barcelona: Ariel

Paye, J-C. (2008). El final del Estado de derecho, la lucha antiterrorista: del estado de excepción a la dictadura. Hondarribia (Gipuzkoa): Hiru.

Pawels, P. (2004). El mito de la guerra buena. EEUU en la Segunda Guerra Mundial. Hondarribia (Gipuzkoa): Hiru.

Pisano, I. (2011). "Libia, testimonios sobre violaciones cometidas por los rebeldes, o 'Más mentiras de la guerra"'. Ojos para la Paz, 4 de octubre. http://www.ojosparalapaz.com/libiatestimonios-sobre-violaciones-cometidas-por-los-rebeldes-o-mas-mentiras-de-la-guerra/ (visita 9-12-2019).

Spinoza, B. (2003). Tratado teológico-político. Madrid: Alianza.

Spinoza, B. (2004). Tratado político. Madrid: Alianza.

\section{Filmografía documental}

Fracassi F. y F. Trento (2008). Zero. Perché la versione ufficiale sull'11/9 è un falso. (basado en el libro de Giulietto Chiesa). Thomas Torelli/TPF Telemaco. https://www.pandoratv.it/category/fuoridamatrix/11-settembre-fuoridamatrix/ (visita 9-122019).

Pilger, J. (2007). The war on democracy. Youngheart Entertainment/Granada/Michael Watt. http://johnpilger.com/videos/the-war-on-democracy-versi-n-en-espa-ol- (visita 9-12-2019).

Pilger, J. (2010). La guerra que usted no ve. Dartmouth Films. http://johnpilger.com/videos/thewar-you-dont-see (visita 9-12-2019). 